\title{
Synthesis and reactivity over molybdenum carbide crystallites
}

\author{
Jeong-Gil Choi ${ }^{\dagger}$ \\ Department of Nano-Bio Chemical Engineering, HannamUniversity, Taejon 305-811, Korea
}

(Received February 16, 2010)

(Revised March 14, 2010)

(Accepted April 2, 2010)

\begin{abstract}
The synthesis and reactivities of molybdenum carbide crystallites were examined in this study. Especially, the effect of synthesis conditions were scrutinized on the preparation of molybdenum carbide crystallites. In order to perform this purpose, various characterization techniques such as BET surface area and oxygen uptake measurements were employed for the synthesized molybdenum carbide crystallites. First of all, the molybdenum carbide crystallites were synthesized using molybdenum oxide crystallites and methane gas or methane-hydrogen mixture. The experimental results showed that BET surface areas ranged from $7.4 \mathrm{~m}^{2} / \mathrm{g}$ to $31 \mathrm{~m}^{2} / \mathrm{g}$ and oxygen uptake values varied from $8.1 \mu \mathrm{mol} / \mathrm{g}$ to $24.3 \mu \mathrm{mol} / \mathrm{g}$. The Mo compounds were found to be active for ammonia decomposition reaction. Even though there are some molybdenum carbide crystallites that were exceeded by $\mathrm{Pt} / \mathrm{Al}_{2} \mathrm{O}_{3}$ crystallite, the steady state reactivities for other molybdenum carbide crystallites were comparable to or even higher than that determined for the $\mathrm{Pt} / \mathrm{Al}_{2} \mathrm{O}_{3}$ crystallite. These results implied that molybdenum carbide crystallites could be one of the promising crystallites that might be substitutes for Pt-like noble metal crystallites in the petroleum processes.
\end{abstract}

Key words Molybdenum carbide crystallites, BET surface area, Oxygen uptake, Ammonia decomposition reactivity

\section{Introduction}

In these days many researchers have been searching for the substitutes for Pt-based materials. Therefore, transition metal carbide and nitride crystallites were reported to be one of the candidates for that purpose [110]. Molybdenum carbide crystallites ( $\mathrm{MoCx}$ ) have been reported to contain similar surface and electronic properties to noble metal materials. Such similarities as substitutes for the more expensive Pt based crystallites suggest that molybdenum carbide crystallites are promising candidates for further development in the petroleum and chemicals processing industries. It has been shown that molybdenum carbide crystallites can be used in the oxidation [11] and dehydrogenation reactions [12]. Another fascinating feature of molybdenum carbide crystallites is that they can be produced with high surface areas. Conventional preparation methods have only yielded low surface area transition metal carbide crystallites, however, it has been demonstrated that high surface area molybdenum carbide crystallites can be prepared by the temperature programmed reduction of molybdenum oxide in either methane or a methane-hydrogen mixture [13].

\footnotetext{
Corresponding author

Tel: +82-42-629-8841

Fax: +82-42-629-8835

E-mail: choi1002@hotmail.com
}

Based on this above-mentioned background, this study was aimed at examining the effect of synthesis parameters on the structural properties and chemisorption uptake capacity of molybdenum carbide crystallites, and evaluating the reactivity of ammonia decomposition. For this purpose, the three experimental variables examined were (1) heating rates, (2) molar hourly space velocity (MHSV), and (3) gas compositon. Particular attention was also given to the effects of preparative conditions on the BET surface area and oxygen chemisorption uptake. Finally, in order to evaluate the reactivity of molybdenum carbide crystallites the measurements of ammonia decomposition reaction were also utilized.

\section{Experimental}

The reactor used in this study to synthesize the molybdenum carbide crystallites was made of a quartz tube fitted with a quartz frit located 12 inches from the top fitted with a cooling water jacket to cool the exiting reaction gases. The size of reactor was 25 inches long and had a diameter of $0.625 "$. Reaction temperatures reached $1313 \mathrm{~K}$ so both the quartz tube and the cooling jacket were needed. The section of the reactor containing the frit and reaction materials was placed inside a Thermocraft Model 132 furnace controlled by an Omega, series CN2010 programmable temperature controller 
Table 1

Synthesis conditions of molybdenum carbide crystallites

\begin{tabular}{llll}
\hline Sample & Heating rate $(\mathrm{K} / \mathrm{h})$ & $\mathrm{H}_{2} / \mathrm{CH}_{4}$ ratio & $\mathrm{MHSV} \mathrm{CH}_{4}\left(\mathrm{~h}^{-1}\right)$ \\
\hline MC-1 & 120 & 1.04 & 70 \\
$\mathrm{MC}-2$ & 60 & 1.04 & 70 \\
$\mathrm{MC}-3$ & 120 & 0 & 70 \\
$\mathrm{MC}-4$ & 60 & 0 & 70 \\
$\mathrm{MC}-5$ & 120 & 1.04 & 35 \\
$\mathrm{MC}-6$ & 60 & 1.04 & 35 \\
$\mathrm{MC}-7$ & 120 & 0 & 35 \\
$\mathrm{MC}-8$ & 60 & 0 & 35 \\
\hline
\end{tabular}

using a chromel-alumel thermocouple to monitor the temperature. Helium was purified by using a Matheson, 6406 filter to remove $\mathrm{O}_{2}$ and water. Gas flow was controlled using needle valves and the flow rates were measured by a bubble flow meter. The raw material of molybdenum oxide was purchased from Alpha chemicals at a purity of $99.9985 \%$.

A series of eight crystallites were synthesized according to the statistical method given in Table 1 in order to examine the influence of the heating rate, the molar hourly space velocity, and the reaction gas composition on the synthesis of molybdenum carbide crystallites. Molar hourly space velocity (MHSV) is defined as the ratio of the molar flow rate of $\mathrm{CH}_{4}$ to the moles of $\mathrm{MoO}_{3}$. To synthesize the molybdenum carbide crystallites, first glass wool was packed on the quartz frit in the reactor tube. A measured amount of Mo oxide was then placed on top. The reactor was placed in the furnace with air-tight seals on top and bottom providing the gas inlet and outlet, respectively. Once this was accomplished, the gas flow was then started. The furnace was heated to $1073 \mathrm{~K}$ in 90 minutes. Then it was heated to $1313 \mathrm{~K}$ using one of the two variable heating rates and held at this temperature for 1 hour. The reactor was then allowed to cool rapidly by removing it from the furnace. When the reactor reached room temperature, the gas was switched to He for 30 minutes, then to $1 \% \mathrm{O}_{2} / \mathrm{He}$ for a 2 hour passivation period. The molybdenum carbide crystallite was then collected and characterized.

The measurements of BET surface areas were performed using a Quantasorb ${ }^{\circledR}$ machine. The standard pretreatment of the molybdenum carbide crystallites consisted of heating the sample in pure $\mathrm{H}_{2}$ gas at a flow rate of 20 $\mathrm{cc} / \mathrm{min}$ for 3 hour at a temperature of $673 \mathrm{~K}$ to remove the passivation layer and other impurities. After the 3 hour period had elapsed, the catalyst was then outgassed at a flow rate of $20 \mathrm{cc} / \mathrm{min}$ in pure He gas at a temperature of $673 \mathrm{~K}$ for 5 minutes. When the 5 minute period had elapsed, the sample was allowed to cool to room temperature. Once the catalyst had reached room temperature, the gas sent through the sample cell was switched to a mixture of $29.3 \% \mathrm{~N}_{2} / \mathrm{He}$ at a flow rate of $20 \mathrm{cc} / \mathrm{min}$. Next, the attenuation of the Quantasorb ${ }^{\circledR}$ machine was set to give a peak height of about $60-90 \%$ of full scale. The next step in the procedure was that the catalyst sample was immersed in a dewar of liquid $\mathrm{N}_{2}$ and the adsorption part of the BET method was then performed. A peak height and count was then determined by the Quantasorb ${ }^{\circledR}$ machine. Next, desorption was performed by lowering the dewar and hot-air heating the catalyst sample to room temperature. A peak height and the count was once again determined. A calibration was then performed by injecting a known amount of $\mathrm{N}_{2} / \mathrm{He}$ gas, determined by the attenuation setting, into the Quantasorb ${ }^{\circledR}$ machine which then gave a peak height and count. The adsorption, desorption, and calibration steps were then performed two more times to minimize error. The catalyst sample was then removed from the machine and weighed. The oxygen uptake experiment was also performed using the Quantasorb ${ }^{\circledR}$ machine. The catalyst was pretreated the exact same way as in the BET experiment but the He gas was left on for ten minutes rather than five. Once the pretreatment was complete, the He gas was left flowing for the remainder of the experiment. The $\mathrm{O}_{2}$ uptake experiment was then performed at $351 \mathrm{~K}$. The attenuation of the Quantasorb ${ }^{\circledR}$ machine was then set at 2 and $0.5 \mathrm{cc}$ injections of a mixture of $9.98 \% \mathrm{O}_{2} / \mathrm{He}$ gas were then made. The injections were then repeated until a constant count on the machine was achieved for about 5 straight injections. The sample was then removed from the machine and weighed.

The reactivities over molybdenum carbide crystallites with approximately $0.2 \mathrm{~g}$ loaded in the reactor were measured for ammonia decomposition reaction. Before measuring reactivity, the sample was reduced using $\mathrm{H}_{2}$ from room temperature to $673 \mathrm{~K}$ at a rate of $0.033 \mathrm{~K} / \mathrm{s}$, held at $673 \mathrm{~K}$ for at least 14 hours then cooled to the reaction temperature. After reduction, atmospheric pressure of $\mathrm{NH}_{3}(99.995 \%)$ was used for $\mathrm{NH}_{3}$ decomposition reaction where the same inlet space velocity based on the bed volume was $7,500 \mathrm{~h}^{-1}$. The reactivities were measured at temperatures between 623 and $823 \mathrm{~K}$. The reactor effluent was analyzed using an on-line Donam gas chromatograph (DS 6200) equipped with both flame ionization and thermal conductivity detectors. The products were separated using Porapak Q packed columns (80/100, 8'x1/8",CRS) connected to a gas chromatography detector. 


\section{Results and Discussion}

In this work all eight reactions produced dark gray powders that were mostly MoC. The most important trend in the synthesis of molybdenum carbide crystallites appears to be getting the gas dispersed through the plug of solid material, especially with slower heating rates. With the gas dispersed evenly through the reactor, the solid crystallite growth begins simultaneously throughout the solid leading to smaller crystallite sizes. If the gas is not dispersed well, less crystallites begin and grow larger. Also, fast heating rates and low MHSVs also caused small crystallite sizes. This would have to be caused by the temperature rising fast enough to overcome the crystallite growth trends. If the temperature rises fast enough, it will begin reactions throughout the solid faster. Then the reaction can spread from the existing carbide. To synthesize carbides with larger crystallite sizes the opposite trends must be followed. The goal then would be to react the material before the gas could penetrate and saturate the solid reactants.

In this study, the molybdenum carbide crystallites were prepared using molybdenum oxide and methane gas or methane-hydrogen mixture and their BET surface areas ranged from $7.4 \mathrm{~m}^{2} / \mathrm{g}$ to $31 \mathrm{~m}^{2} / \mathrm{g}$. When the molybdenum carbide crystallites were synthesized in pure $\mathrm{CH}_{4}$, the highest specific surface areas were obtained with the high heating rate of $120 \mathrm{~K} / \mathrm{h}$ and low space velocity of $35 \mathrm{hr}^{-1}$. A possible reason for the effect of lower MHSV on surface area in pure $\mathrm{CH}_{4}$ could be due to the fact that $\mathrm{CH}_{4}$ was in contact with the molybdenum oxide for a greater period of time which would result in a greater conversion of the lower surface area molybdenum oxide to molybdenum carbide crystallite. Overall, the highest specific surface area molybdenum carbide crystallites were produced in pure $\mathrm{CH}_{4}$ when the heating rate was $120 \mathrm{~K} / \mathrm{hr}$ and the molar hourly space velocity was $35 \mathrm{hr}^{-1}$. As can be seen in Table 2, when the molybdenum carbide crystallites were synthesized in an $\mathrm{H}_{2} / \mathrm{CH}_{4}$ mixture, the highest surface areas were obtained when the heating rate and the molar hourly space velocity were $120 \mathrm{~K} / \mathrm{hr}$ and $70 \mathrm{hr}^{-1}$, respectively. The most likely reason for the effect of greater MHSV on specific surface area is the rapid removal of water vapor from the vicinity of the reacting solid. Water vapor can cause hydrothermal sintering which lowers the surface area [1-10]. The effect of greater heating rate on surface area is that the reaction rate increased which also increased the conversion of molybdenum oxide to molybdenum carbide crystallites. Similarities in the prepa-
Table 2

Sorption properties of molybdenum carbide crystallites*

\begin{tabular}{lllll}
\hline Sample & $\begin{array}{l}\text { Surface area } \\
\left(\mathrm{m}^{2} / \mathrm{g}\right)\end{array}$ & $\begin{array}{l}\mathrm{O}_{2} \text { uptake } \\
(\mu \mathrm{mol} / \mathrm{g})\end{array}$ & $\begin{array}{l}\text { Site density* } \\
\left(\mathrm{m}^{-2}\right) 10^{-7}\end{array}$ & $\begin{array}{l}\text { Surface } \\
\text { coverage }(\%)\end{array}$ \\
\hline MC-1 & 22.3 & 16.7 & 10.2 & 16 \\
$\mathrm{MC}-2$ & 12.1 & 12.2 & 6.5 & 10 \\
$\mathrm{MC}-3$ & 7.4 & 8.1 & 4.9 & 8 \\
$\mathrm{MC}-4$ & 5.5 & 8.9 & 7.1 & 11 \\
$\mathrm{MC}-5$ & 17.2 & 11.8 & 7.9 & 6 \\
$\mathrm{MC}-6$ & 9.3 & 9.9 & 8.9 & 5 \\
$\mathrm{MC}-7$ & 31 & 24.3 & 11.3 & 19 \\
$\mathrm{MC}-8$ & 25 & 23.5 & 9.8 & 13 \\
\hline
\end{tabular}

*Based on $\mathrm{O}_{2}$ uptake at $195 \mathrm{~K}$.

ration of transition metal carbide crystallites such as tantalum, titanium, and niobium carbide crystallites have been also found and previously published by the same group $[3,5,6]$.

Table 2 shows the sorption properties over molybdenum carbide crystallites. Oxygen uptake was taken as a measure of the number of potential active sites on the molybdenum carbide crystallites. Depending upon the different molybdenum carbide crystallites, the different values of oxygen uptake were measured. These results implied that the molybdenum carbide crystallite contains a potential of reactivity property as well as its property strongly depends on the synthesis conditions. Oxygen site densities were determined from the $\mathrm{O}_{2}$ uptakes and the BET surface areas. The $\mathrm{O}_{2}$ site density averages and $8.3 \times 10^{7} \mathrm{O}_{2} / \mathrm{m}^{2}$. Assuming a $1: 1 \mathrm{Mo}: \mathrm{O}$ stoichiometry, surface coverages averaged $\sim 11 \%$. Fig. 1 also showed that the relationship between oxygen uptake and BET surface area is somewhat linear. This result suggests that

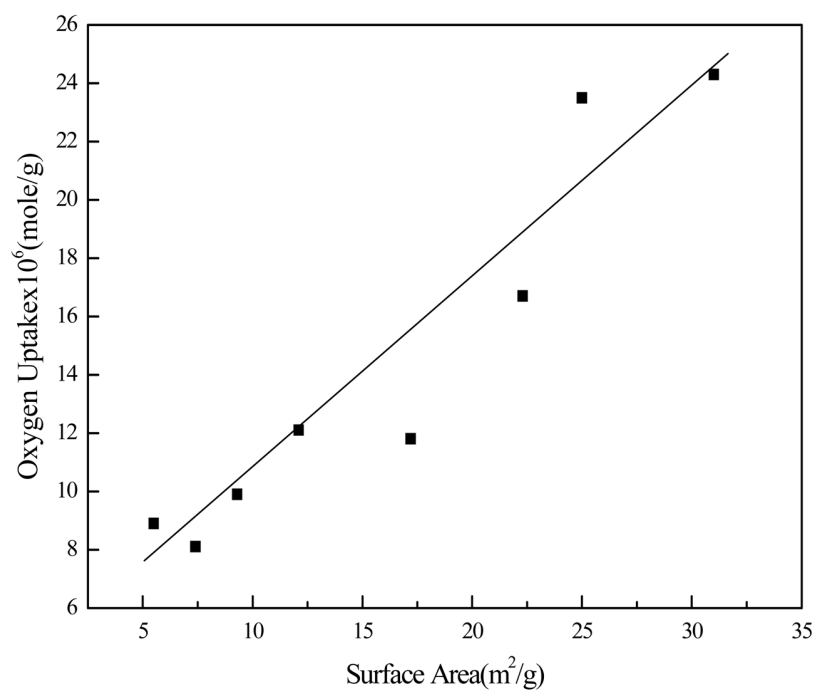

Fig. 1. The relationship between surface area and oxygen uptake for molybdenum carbide crystallites. 
oxygen was a nonselective adsorbate to the molybdenum carbide crystallites. The linear relationship between oxygen uptake and BET surface area in molybdenum carbide crystallites is similar to that in molybdenum nitride crystallites [13]. These results indicated that in the case of the same metal, molybdenum-based carbide and nitride crystallites the capacity of adsorbate increases almost proportionally with the increase of surface area produced by insertion of carbon or nitrogen into the base meatal of molybdenum. These findings are very important since in the petroleum process the reaction properties of the resultant transition metal carbide and

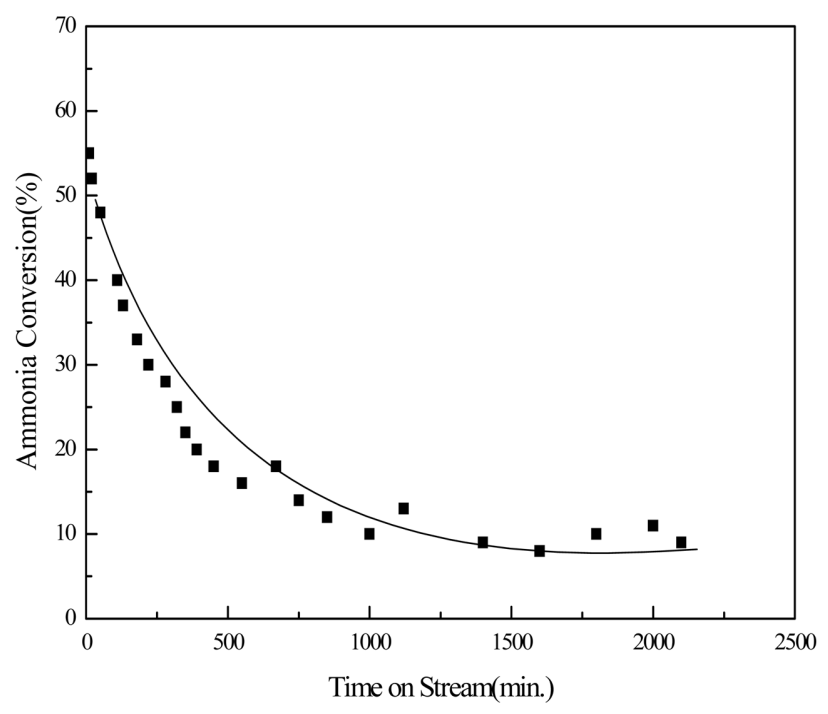

Fig. 2. Typical ammonia conversion (\%) as a function of time on stream.

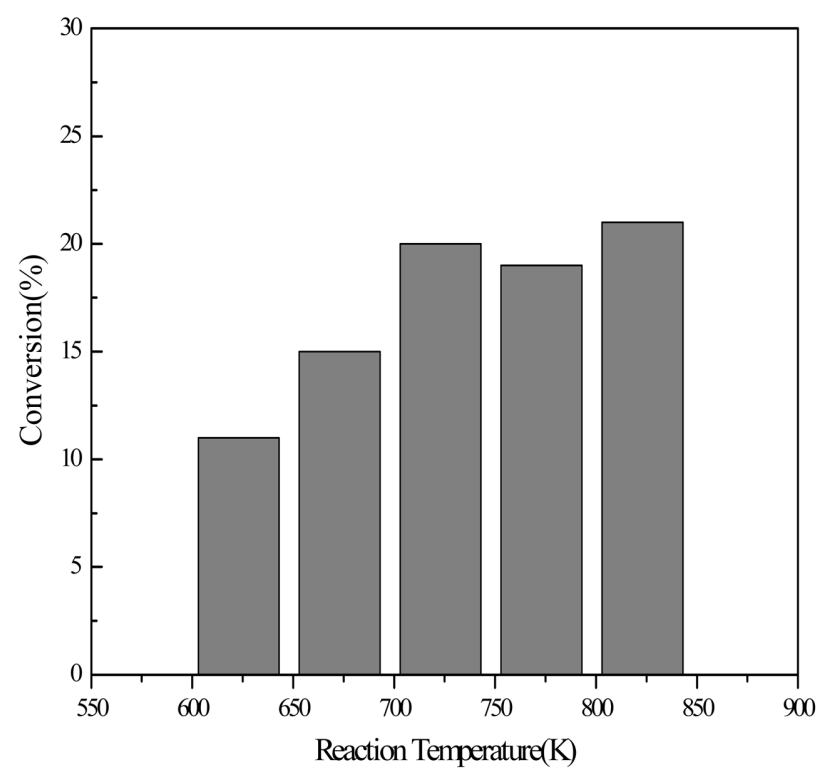

Fig. 3. Ammonia decomposition conversion as a function of temperature over MC-1 (at 623, 673, 723, 773, and $823 \mathrm{~K}$ ). nitride crystallites are closely related to their preparation with the high surface areas.

All of the molybdenum carbide crystallites synthesized in this study were found to be active for ammonia decomposition reaction. The freshly prepared molybdenum carbide crystallites exhibited the highest initial conversion, but then gradually lost activity with time. The $\mathrm{NH}_{3}$ decomposition reaction rates decreased to the steadystate activities, and then remained constant for several hours. Fig. 2 shows the typical relationship between the conversion and time on stream over the molybdenum carbide crystallites. It is general to see this kind of relation between the initial conversion decrease and reaction time for all the molybdenum carbide crystallites prepared in this study. Fig. 3 shows the effect of reaction temperature on the conversion, indicating that the conversion increased with the increase of temperature. However, above $723 \mathrm{~K}$ no temperature effects were observed for molybdenum carbide crystallites. Table 3

Table 3

Reactivities of molybdenum carbide crystallites for $\mathrm{NH}_{3}$ decomposition

\begin{tabular}{llll}
\hline \multicolumn{3}{c}{ Sample Surface area $\left(\mathrm{m}^{2} / \mathrm{g}\right) \mathrm{O}_{2}$ uptake $(\mu \mathrm{mol} / \mathrm{gr})$ Conversion $(\%)$} \\
\hline MC-1 & 22.3 & 16.7 & 19 \\
$\mathrm{MC}-2$ & 12.1 & 12.2 & 16 \\
$\mathrm{MC}-3$ & 7.4 & 8.1 & 13 \\
$\mathrm{MC}-4$ & 5.5 & 8.9 & 15 \\
$\mathrm{MC}-5$ & 17.2 & 11.8 & 22 \\
$\mathrm{MC}-6$ & 9.3 & 9.9 & 16 \\
$\mathrm{MC}-7$ & 31 & 24.3 & 31 \\
$\mathrm{MC}-8$ & 25 & 23.5 & 26 \\
\hline
\end{tabular}

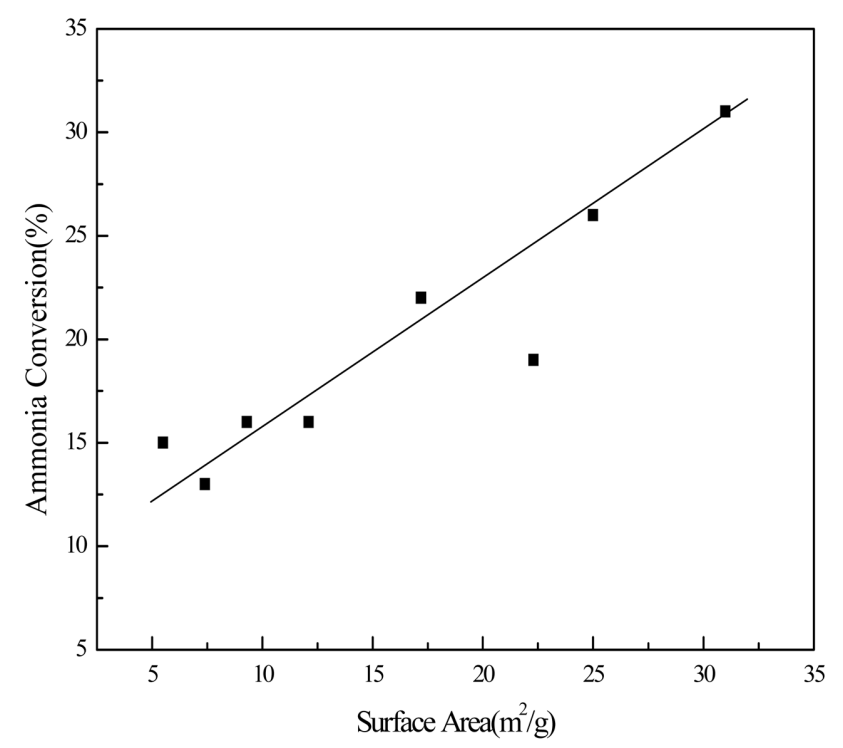

Fig. 4. The conversion versus surface area of molybdenum carbide crystallites. 
shows the steady state activities for all molybdenum carbide crystallites. All of the molybdenum carbide crystallites showed the linear relationship between surface area and reactivity of ammonia decomposition (Fig. 4). This indicated that the surface area is linearly related to the reactive site of these crystallites for ammonia decomposition. Subsequently, these results suggested that the ammonia decomposition reaction was structure-sensitive for molybdenum carbide crystallites. Previously, Choi and coworkers also reported that ammonia decomposition was structure-sensitive over vanadium and niobium carbide crystallites [10, 14].

Among the molybdenum carbide crystallites, MC-7 had the highest steady state reactivity for $\mathrm{NH}_{3}$ decomposition. The MC-7 crystallites was $\sim 2.4$ times more reactive than MC-3, having the lowest activity. This suggested that the reactive species in the MC-3 crystallites was different from that in the MC-7 crystallites. Similar results were observed by Choi et al. that the molybdenum nitride crystallites having the high surface area showed the highest activity over pyridine hydrodenitrogenation [12]. In order to compare with the activities of molybdenum carbide crystallites a reactivity of $\mathrm{Pt} / \mathrm{Al}_{2} \mathrm{O}_{3}$ was measured to be $35 \%$. Even though there are some molybdenum carbide crystallites that were exceeded by $\mathrm{Pt} / \mathrm{Al}_{2} \mathrm{O}_{3}$ sample, the steady state reaction activities for other molybdenum carbide crystallites were comparable to or even higher than that determined for the $\mathrm{Pt} / \mathrm{Al}_{2} \mathrm{O}_{3}$ sample. These results exhibited that the characteristics of reactive sites in the molybdenum carbide crystallites were similar to those in the group 8-10 metal based materials. Furthermore, these results suggested that the molybdenum carbide crystallites can be used for the substitutes of the precious metal crystallites that have been utilized in many petroleum industries.

\section{Conclusions}

The molybdenum carbide crystallite was successfully synthesized using all eight synthesis reaction conditions. The most important trend influencing the BET surface area in the synthesis of molybdenum carbide crystallite is a combination of heating rate and molar hourly space velocity. In genera1 molybdenum carbide crystallites produced under various synthesis conditions have relatively low surface areas when compared to other crystallites. The surface area of prepared molybdenum carbide crystallites was increased by temperature programmed reduction of molybdenum oxide in pure methane with a lower molar hourly space velocity and a higher heating rate. The molybdenum carbide crystallites prepared under different synthesis conditions show little oxygen uptake but the most oxygen uptake occurs when the molybdenum carbide crystallite is synthesized in a hydrogen methane mix at a high molar hourly space velocity, and a high heating rate. The molybdenum carbide crystallites were found to be reactive for ammonia decomposition reaction. Even though there are some molybdenum carbide crystallites that were exceeded by $\mathrm{Pt} / \mathrm{Al}_{2} \mathrm{O}_{3}$ sample, the steady state reaction activities for other molybdenum carbide crystallites were comparable to or even higher than that determined for the Pt/ $\mathrm{Al}_{2} \mathrm{O}_{3}$ sample. These results suggested that the molybdenum carbide crystallites can be used for the substitutes of the precious metal materials that have been utilized in many petroleum industries.

\section{Acknowledgement}

This paper has been supported by 2010 Hannam University Research Fund (starting from March 1, 2010 through Feb. 28, 2011).

\section{References}

[1] J.-G. Choi, "The influences of surface composition on HDN activities of molybdenum nitrides", Journal of Industrial and Engineering Chemistry 8(1) (2002) 1.

[2] J.-G. Choi and J.-S. Kim, "Synthesis and catalytic properties of niobium carbides", Journal of Industrial and Engineering Chemistry 7(5) (2001) 332.

[3] J.-G. Choi and P. Selvam, "Synthesis and reactivity of titanium carbide", Bulletin of the Catalysis Society of India 11(4) (2001) 1.

[4] J.-G. Choi, "The surface properties of vanadium compounds by XPS", Applied Surface Science 148 (1999) 64.

[ 5 ] J.-G. Choi, "The influence of surface properties on catalytic activities of tantalum carbides", Applied Catalysis 184(2) (1999) 189.

[6] J-G. Choi, H.J. Lee, Y.-J. So, Y.-K. Yoon, J.-S. Kim and D.-S. Choi, "Synthesis and catalytic properties of niobium carbides: The effect of synthesis conditions", J. of Sci. Res. Inst. Hannam Univ. 29 (1999) 417.

[7] J.-G. Choi, "Ammonia decomposition over vanadium carbide catalysts", Journal of Catalysis 182 (1999) 104.

[ 8 ] J.-G. Choi, H.-G. Oh and Y.-S. Baek, "Tantalum carbide hydrodenitrogenation catalysts", Journal of Industrial and Engineering Chemistry 4(2) (1998) 94.

[9] J.-G. Choi, H.-G. Oh, Y.-J. So, Y.-K. Youn, J. Ha and Y.-S. Baek, "Ammonia decomposition over vanadium compounds", Journal of Sci. Res. Inst. Hannam Univ. 
28 (1998) 1.

[10] J.-G. Choi, J. Ha and J.-W. Hong, "Synthesis and catalytic properties of vanadium interstitial compounds", Applied Catalysis 168 (1998) 47.

[11] N.I. I1'chenko, Oxidative Catalysis on Transition-Metal Carbides, Kinetika i Kataliz 18(1) (1977) 153.

[12] GV. Samsonov, T.G. Bulankovs, P.A. Khodak, E.M. Prshedromirskaya, V.S. Sinel'nikova and V.M. Sleptsov, Catalytic Properties of Carbides and Silicides of Transi- tion Metals in the Dehydrogenation of EthyIbenZene to Styrene, Kinetika i Kataliz 10(5) (1969) 1057.

[13] J.-G. Choi, R.L. Curl and L.T. Tompson, "Molybdenum nitride catalysts I. Influence of the synthesis factors on structural properties", J. Catal. 146 (1994) 218.

[14] J.-G Choi, "Preparation and characterization of Nb carbide crystallites", Journal of the Korean Crystal Growth and Crystal Technology 19(3) (2009) 125. 